\title{
Are Credit Markets Still Local? Evidence from Bank Branch Closings
}

\author{
Hoai-Luu Q. Nguyen
}

Online Appendix

\section{OA.1 Robustness}

Appendix Table A.2 shows that the baseline results from Section IV are robust to several changes.

First, the standard practice in much of the finance literature is to define local banking markets at the level of the MSA or non-MSA county. Garmaise and Moskowitz (2006) argue that this convention has been driven by data availability, and that evidence suggests local markets are likely to be much smaller. ${ }^{1}$ As this paper's identification strategy relies on withincounty comparisons, this may be a concern if the results are driven by comparisons between tracts located very far apart. Panel A shows the results are robust to redefining the relevant market to be all Control tracts located with 25, 20, or even 15 miles.

Second, the reporting threshold for CRA was increased from $\$ 250$ million to $\$ 1$ billion in 2005, which falls in the middle of the sample period. This is potentially a concern if the share of banks within the $\$ 250$ million - $\$ 1$ billion range differs systematically between Exposed and Control tracts. Panel B, however, shows the results are robust to controlling for the tract-level market share of banks who were excluded from CRA starting in 2005.

Third, I check that the results are not driven by missing data. Section II notes that the process of geocoding the FDIC data results in a small fraction of unmapped observations. These

\footnotetext{
${ }^{1}$ Garmaise, Mark J. and Tobias J. Moskowitz, "Bank Mergers and Crime: The Real and Social Effects of Credit Market Competition," The Journal of Finance, 2006, 61(2), 495-538.
} 
branch locations are necessarily dropped from my sample because the data fields required to pinpoint their location are missing. Column 6 in Appendix Table A.1 shows that the percentage of unmapped observations in counties exposed to the large bank mergers in my sample is much lower that what we observe in the full FDIC data, and Panel $\mathrm{C}$ of Appendix Table A.2 shows that the baseline results are robust to dropping the top decile of Exposed counties ranked according to their percentage of unmapped SOD observations. ${ }^{2}$

Panel D shows the results are robust to redefining the Control group to include only tracts that had a branch from one of the banks that eventually went through a merger.

Finally, Appendix Table A.3 shows that the baseline results are robust to several subsampling exercises and are not driven by outliers in the data. Specification 2 drops observations where the number of loans originated is 0 . Specifications 3 and 4 remove the observations in the top and bottom $5 \%$ of the distribution for annual loan originations (recall, as well, that the data are already winsorized at the $1 \%$ level). Specifications 5 and 6 assess the impact of removing the $5 \%$ smallest and largest tracts, where tracts are ranked according to their level of small business lending in 2000. Specifications 7 and 8 conduct the analogous exercise where tract size is based on the average level of lending over all pre-merger years. The baseline results remain stable across these subsamples.

\section{OA.2 Crisis Mergers}

This section examines the effect of branch closings resulting from mergers that occurred during the financial crisis, which are excluded from the baseline sample as they were fundamentally very different types of transactions. As Appendix Table A.6 shows, the crisis mergers were acquisitions of failed institutions that involved heavy involvement from federal regulators (I exclude mergers that occurred after 2009 as the data on outcomes only extend to 2012). Of the eight mergers included in this sample, five received direct financial assistance from the FDIC. Even those that did not receive financial assistance, such as the 2008 acquisition of Wachovia by Wells Fargo, drew substantial regulatory involvement and scrutiny. In contrast, none of the

\footnotetext{
${ }^{2}$ It is also worth noting that very few observations are dropped in the process of merging the FDIC data to HMDA and CRA data - only $0.3 \%$ and $0.2 \%$, respectively.
} 
mergers in the baseline sample received FDIC assistance. As banks' post-merger behavior may differ in meaningful ways depending on the degree of regulatory scrutiny they are subjected to, I examine these mergers separately.

Appendix Figure A.5 shows that the first stage for the exposure instrument still applies for the 2008-9 crisis mergers: Exposed tracts are more likely to experience branch closings relative to Control tracts in the period immediately after the merger. Appendix Table A.7, however, shows there is no effect of the closing on credit supply to local small businesses. In fact, the point estimates suggest local small business lending increases slightly in Exposed tracts in the post-closing period. As with the baseline results, there is no significant effect on local mortgage lending.

A potential explanation for the contrast between these results and those obtained from the baseline sample is that greater regulatory oversight of the 2008-9 mergers constrained these banks' post-merger behavior. Not only did the mergers themselves entail greater oversight, but this was also a period when regulators would have been particularly alert to any actions that might restrict local credit supply.

\section{OA.3 Mortgage Results by Tract Median Income}

Section IV.B.3 shows that the post-closing decline in small business lending is more severe in marginalized neighborhoods. This section examines whether the impact of closings on local mortgage lending varies by tract demographic - in particular, by tract median income.

Figure 4 shows closings have a very minimal impact on local mortgage lending: originations dip when the closing occurs, but recover in step with the entry of a new branch. Appendix Figure A.6 shows the results of separately estimating the effects of closings in tracts with median income either above or below the sample median. The top left panel shows that belowmedian tracts are more heavily affected by a closing. These tracts drive the overall pattern in mortgage originations observed in Figure 4. Moreover, the top right panel shows the same pattern is observed in mortgage applications in below-median tracts: applications fall when the closing occurs, but recover shortly thereafter. Putting these together, the bottom panel shows 
mortgage approval rates in both above- and below-median income tracts are flat through the treatment period.

Appendix Figure A.6 shows how the impact of closings on mortgage lending varies across tracts with different income levels. Appendix Figures A.7 and A.8 examine whether, within lowincome tracts, there is variation in which borrowers are more severely affected by the closing. Both show that there is no meaningful change in the average characteristics of who is applying, and receiving, mortgages after the closing.

These results suggest that low-income tracts tend to have mortgage markets that are more localized relative to those in wealthier neighborhoods and are, therefore, more vulnerable to disruption when a local branch closes. The disruption, however, does not appear to be driven by the destruction of lending relationships. Within tracts, there is no evidence that the borrowers we would expect to be more dependent on relationships (i.e., low income, minority, or less creditworthy borrowers) are disproportionately impacted by a closing. Instead, the initial decline may be related to capacity constraints in lending, which are alleviated when a new bank enters the market. 


\section{Appendix Figures}

Figure A.1: Geographic Distribution of Exposed Counties

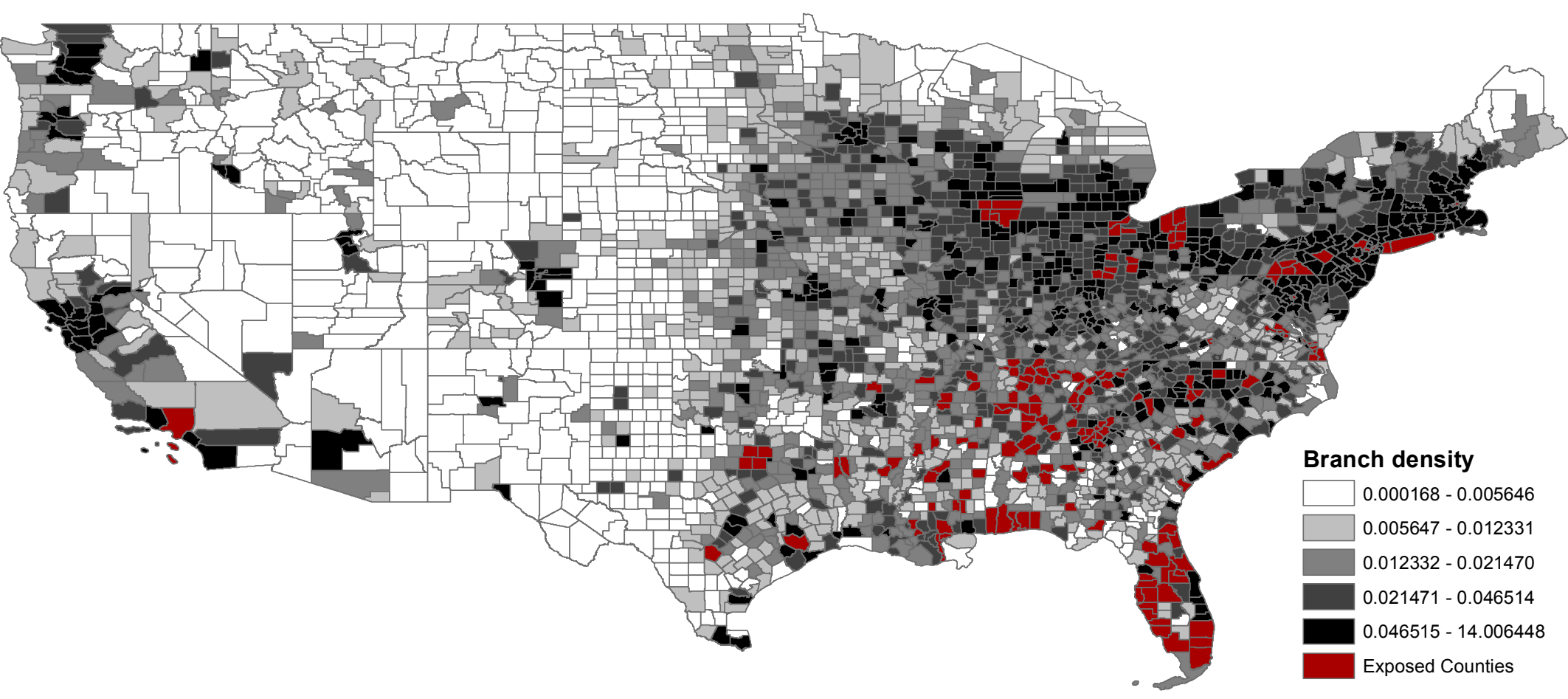

Source: FDIC, author's own calculations. Figure shows the geographic distribution of counties used in the baseline sample. The Exposed counties are shaded in red. All other counties are shaded according to branch density, which is branches per square mile. 
Figure A.2: Branch Closings in Buyer Only and Target Only Tracts

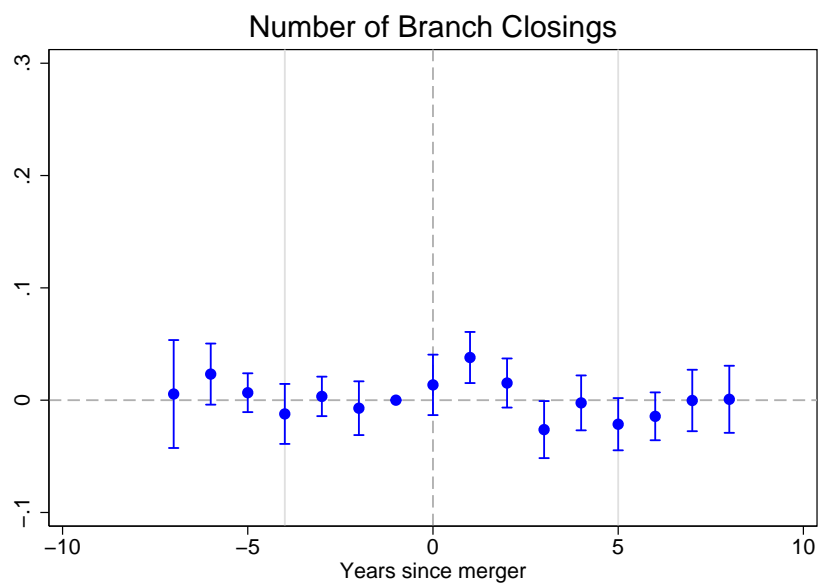

Source: FDIC, author's own calculations. Figure plots the first stage relationship between exposure to consolidation and the incidence of branch closings where the treated group is tracts that either had only Buyer branches or only Target branches prior to the merger, obtained from estimating Equation 3. Bars show $95 \%$ confidence intervals. $\tau=0$ is the year the merger was approved by federal regulators, and all coefficients are normalized relative to $\tau=-1$. The vertical lines at $\tau=-4$ and $\tau=6$ denote the range over which the panel is balanced. Robust standard errors are clustered at the county level.

Figure A.3: Sample Distribution of Annual Loan Originations, Net of Fixed Effects
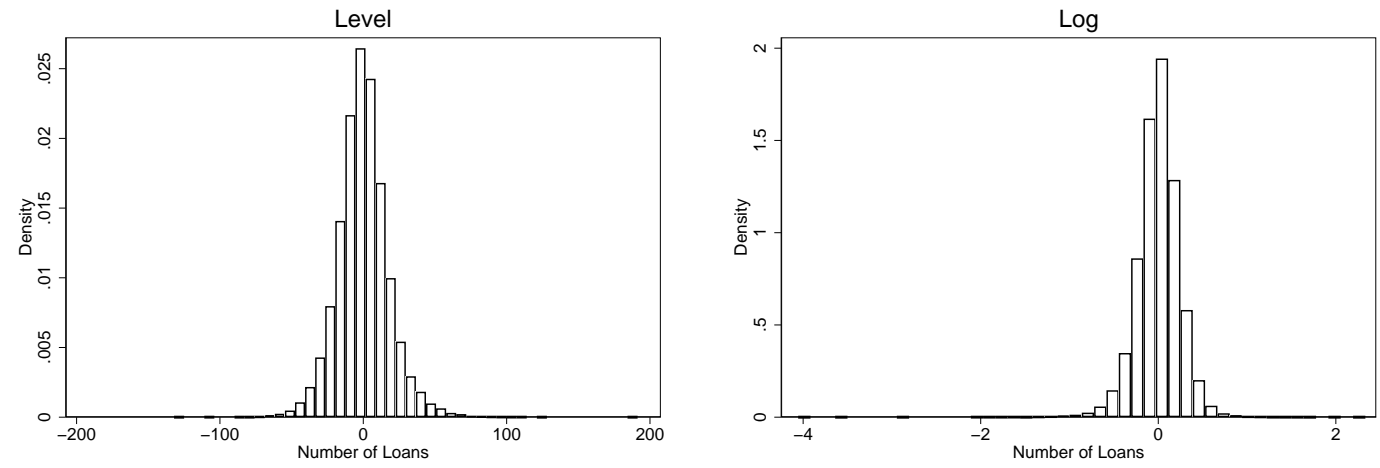

Source: FFIEC, author's own calculations. Figures show histograms of annual tract-level small business loan originations from the estimation sample, net of tract and county-by-year fixed effects. The left plot shows the distribution in levels, while the right plot shows the distribution in logs. 
Figure A.4: Reduced Form Effect on Prices
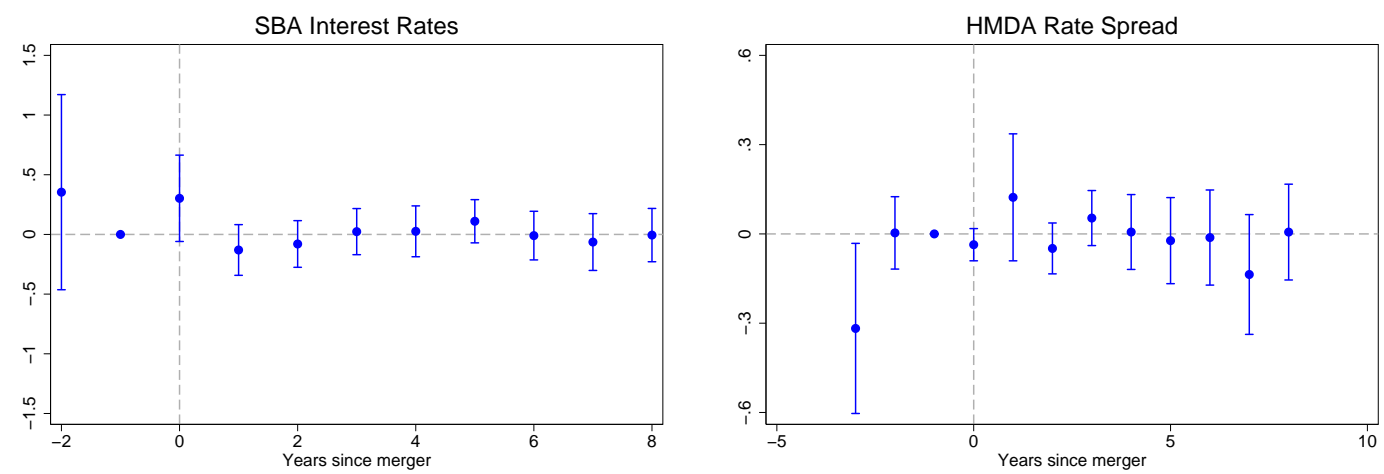

Source: FFIEC, SBA, author's own calculations. Figure plots the reduced form relationship between exposure to consolidation and interest rates on small business loans and mortgages, respectively, obtained from estimating Equation 3 . The left panel uses loan-level data from the SBA's 7(a) loan program, which reports interest rates starting in 2005 . The right panel uses HMDA data, which report the spread between the APR on a loan and the Treasury rate for loans with spreads above a designated threshold. These data are available starting in 2004 . Bars show $95 \%$ confidence intervals. $\tau=0$ is the year the merger was approved by federal regulators, and all coefficients are normalized relative to $\tau=-1$. Robust standard errors are clustered at the county level.

Figure A.5: First Stage, Crisis Mergers

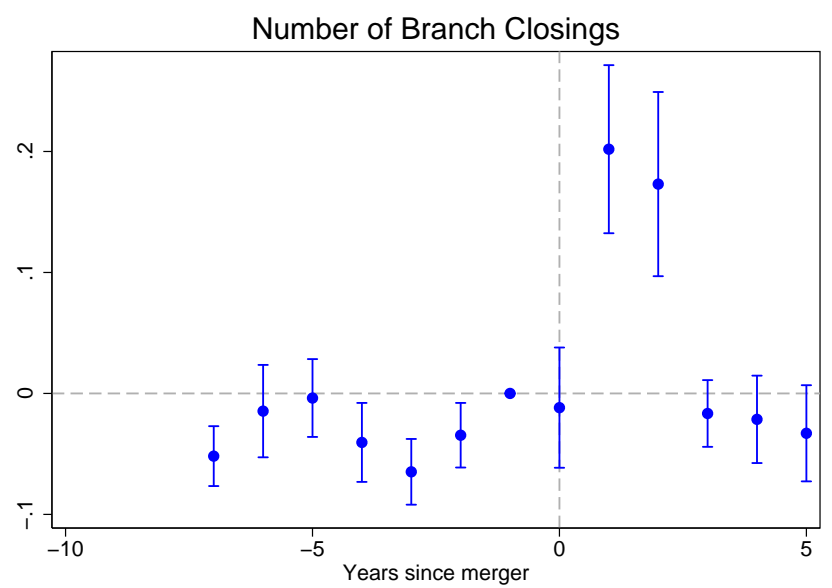

Source: FDIC, author's own calculations. Figure shows estimates of Equation 3 and plots the first stage relationship between exposure to consolidation and the incidence of branch closings using only the mergers shown in Appendix Table A.6. Bars show $95 \%$ confidence intervals. $\tau=0$ is the year the merger was approved by federal regulators, and all coefficients are normalized relative to $\tau=-1$. Robust standard errors are clustered at the county level. 
Figure A.6: Mortgage Results, Above- vs. Below- Median Income
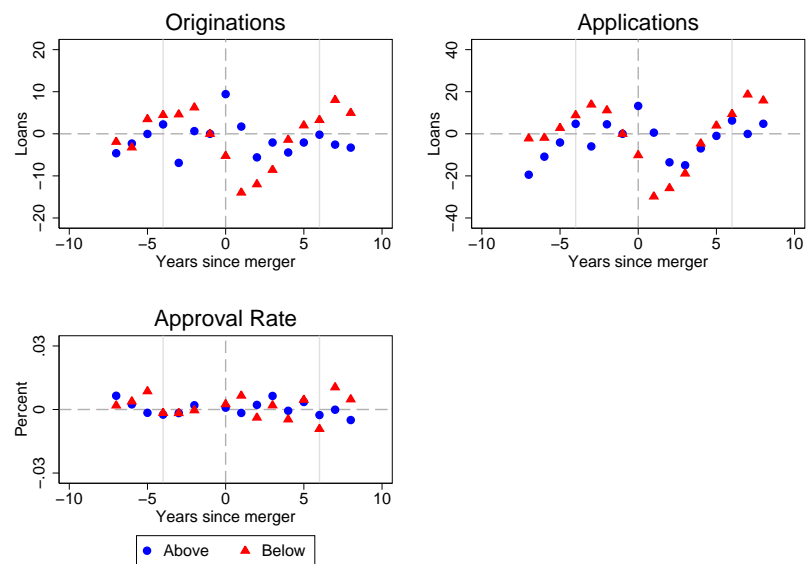

Source: FFIEC, author's own calculations. Figure shows estimates of Equation 3 and plots the reduced form relationship between exposure to consolidation and mortgage originations, applications, and approval rates, respectively, for tracts with median income above (blue circles) and below (red triangles) the sample median. The tract-level approval rate is the ratio of originations to applications. $\tau=0$ is the year the merger was approved by federal regulators, and all coefficients are normalized relative to $\tau=-1$. The vertical lines at $\tau=-4$ and $\tau=6$ denote the range over which the panel is balanced. Robust standard errors are clustered at the county level.

Figure A.7: Characteristics of Mortgage Applications in Low-Income Tracts
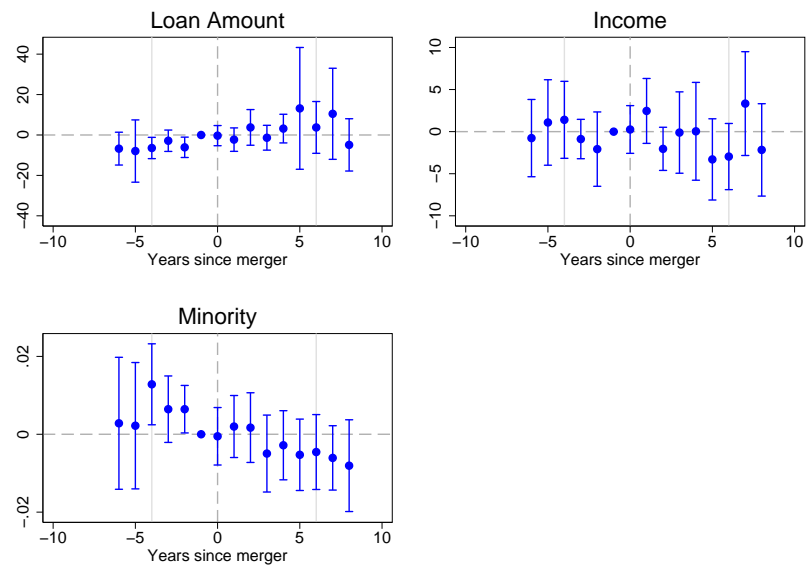

Source: FFIEC, author's own calculations. Figure shows estimates of Equation 3 and plots the reduced form relationship between exposure to consolidation and characteristics of mortgage applications in tracts with median income below the sample median. The plots show results for average loan amount, along with income and minority status of the applicant. Bars show $95 \%$ confidence intervals. $\tau=0$ is the year the merger was approved by federal regulators, and all coefficients are normalized relative to $\tau=-1$. The vertical lines at $\tau=-4$ and $\tau=6$ denote the range over which the panel is balanced. Robust standard errors are clustered at the county level. 
Figure A.8: Characteristics of Mortgage Originations in Low-Income Tracts
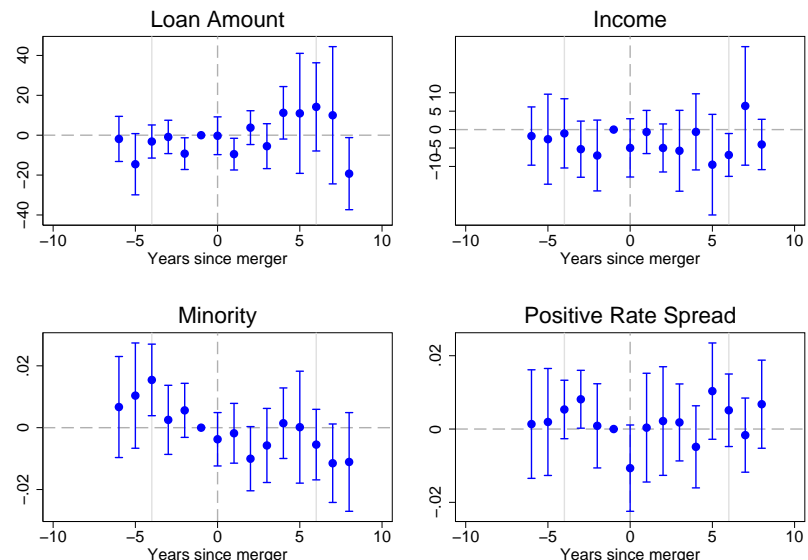

Source: FFIEC, author's own calculations. Figure shows estimates of Equation 3 and plots the reduced form relationship between exposure to consolidation and characteristics of mortgage originations in tracts with median income below the sample median. The plots show results for average loan amount, income and minority status of the applicant, and probability of having a positive rate spread on the loan. Bars show $95 \%$ confidence intervals. $\tau=0$ is the year the merger was approved by federal regulators, and all coefficients are normalized relative to $\tau=-1$. The vertical lines at $\tau=-4$ and $\tau=6$ denote the range over which the panel is balanced. Robust standard errors are clustered at the county level.

Figure A.9: RF Effects on Lending, 2006-2007 Mergers
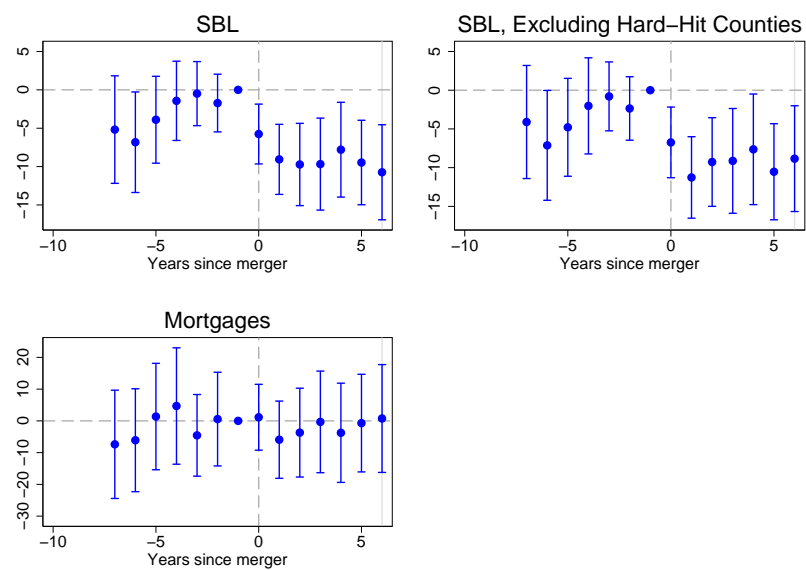

Source: FFIEC, author's own calculations. Figure shows estimates of Equation 3 and plots the reduced form relationship between exposure to consolidation and lending for mergers that were approved in 2006-2007. The top two panels show results for small business lending, where the right panel excludes counties whose peak-to-trough decline in employment over the $2000 \mathrm{~s}$ was more severe than in the median county. The bottom panel shows results for mortgage lending. Estimating Equation 3 with the full set of baseline controls interacted with year dummies as well as tract and county-by-year fixed effects becomes infeasible once I restrict to the smaller sample associated with the 2006-2007 mergers. So the specifications for small business and mortgage lending exclude the baseline controls for fraction college-educated and population density, while the specification excluding hard-hit counties additionally drops the baseline controls for fraction minority and branch growth. Bars show $95 \%$ confidence intervals. $\tau=0$ is the year the merger was approved by federal regulators, and all coefficients are normalized relative to $\tau=-1$. Robust standard errors are clustered at the county level. 


\section{Appendix Tables}

Table A.1: Geocoding Summary Statistics

\begin{tabular}{lccccc}
\hline \hline $\begin{array}{l}(1) \\
\text { Year }\end{array}$ & $\begin{array}{c}(2) \\
\text { Total Branches }\end{array}$ & $\begin{array}{c}(3) \\
\text { Mapped }\end{array}$ & $\begin{array}{c}(4) \\
\text { Unmapped }\end{array}$ & $\begin{array}{c}(5) \\
\text { \% Unmapped }\end{array}$ & $\begin{array}{c}(6) \\
\text { \% Unmapped (MS) }\end{array}$ \\
\hline & & & & & \\
1999 & 84,312 & 77,971 & 6,341 & 7.5 & 4.6 \\
2000 & 85,492 & 79,713 & 5,779 & 6.8 & 3.9 \\
2001 & 86,069 & 80,919 & 5,150 & 6.0 & 3.4 \\
2002 & 86,578 & 82,001 & 4,577 & 5.3 & 2.7 \\
2003 & 87,790 & 85,297 & 2,493 & 2.8 & 2.0 \\
2004 & 89,784 & 87,598 & 2,186 & 2.4 & 1.7 \\
2005 & 92,042 & 90,083 & 1,959 & 2.1 & 1.3 \\
2006 & 94,752 & 93,016 & 1,736 & 1.8 & 0.1 \\
2007 & 97,274 & 95,847 & 1,427 & 1.5 & 0.4 \\
2008 & 99,163 & 98,211 & 952 & 1.0 & 0.1 \\
2009 & 99,550 & 98,856 & 694 & 0.7 & 0.1 \\
2010 & 98,520 & 97,812 & 708 & 0.6 & 0.0 \\
2011 & 98,204 & 97,657 & 547 & 0.6 & 0.1 \\
2012 & 97,337 & 96,774 & 563 & 0.6 & \\
& & & & & \\
\hline
\end{tabular}

Source: FDIC, author's own calculations. Table shows summary statistics for the geocoding procedure used to map branch locations from the FDIC Summary of Deposits to their Census tract. Branch locations are geocoded either by plotting their latitude and longitude, or by matching their street address to those stored in a GIS repository. The former is used whenever possible, but latitude and longitude data are only available beginning in 2008 and can only be matched to a limited number of observations prior to that. As a result, in every year there are observations that cannot be mapped because they have no lat/long data and their street address was either incomplete or invalid and could not be matched to an address in the GIS repository. Column 5 shows the percentage of unmapped observations in the full FDIC data. Column 6 shows the percentage of unmapped observations in the merger sample. 
Table A.2: Robustness Checks

\begin{tabular}{lcc}
\hline \hline & $(1)$ & $(2)$ \\
& $\delta_{R F}$ & Obs. \\
\hline \multirow{2}{*}{ Baseline } & -2.513 & 45,160 \\
& $(0.909)$ & \\
& Panel A: Size of the Banking Market \\
& -2.031 & \\
25-Mile & $(0.195)$ & \\
& & \\
20-Mile & -2.127 & 81,697 \\
& $(0.918)$ & \\
15-Mile & -1.944 & 71,329 \\
& $(0.921)$ &
\end{tabular}

Panel B: 2005 Reporting Change

Control: Share Excl. Banks $\quad-2.523 \quad 45,025$

Panel C: Missing Data

Exclude Top Decile Counties $\quad-2.105 \quad 40,485$

$(0.968)$

Panel D: Redefining the Control Group

Control: Buyer or Target Only $\quad-2.191 \quad 26,547$

$(0.947)$

Source: FFIEC, author's own calculations. Table shows reduced form estimates of Equation 4 where the dependent variable is annual, tract-level small business loan originations. All specifications include the full set of baseline controls interacted with year dummies along with tract and county-by-year fixed effects. The first row is the baseline estimate from Table 7. Panel A shows results from defining local banking markets to be within-county areas of varying size. Panel B shows results when controlling for the tract-level market share of banks who were excluded from CRA reporting starting in 2005. Panel C shows results when dropping the top decile of counties ranked according to their percentage of unmapped FDIC Summary of Deposits data. Panel D shows results when redefining the Control group to include only tracts that had a branch from one of the banks that eventually went through a merger. See Appendix Section A for details. Robust standard errors are clustered at the county level and are in parentheses. 
Table A.3: Removing Outliers

\begin{tabular}{lccc}
\hline \hline & $(1)$ & $(2)$ & $(3)$ \\
& No. Loans & $\$$ Volume $(000 \mathrm{~s})$ & Obs. \\
\hline 1. Baseline & -2.513 & -206.7 & 45,160 \\
& $(0.909)$ & $(77.91)$ & \\
2. No. Loans $=0$ & -2.508 & -206.4 & 45,138 \\
& $(0.908)$ & $(77.86)$ & \\
3. Bottom 5\% of Obs. & -2.319 & -199.0 & 42,979 \\
& $(0.893)$ & $(77.88)$ & \\
4. Top 5\% of Obs. & -1.974 & -203.9 & 42,915 \\
& $(0.860)$ & $(77.09)$ & \\
5. Small Tracts (Year 2000 Levels) & -2.594 & -215.3 & 42,606 \\
& $(0.935)$ & $(81.28)$ & \\
6. Large Tracts (Year 2000 Levels) & -2.670 & -215.3 & 43,682 \\
& $(0.880)$ & $(78.79)$ & \\
7. Small Tracts (Avg. Pre-merger Levels) & -2.486 & -210.0 & 42,853 \\
& $(0.921)$ & $(78.71)$ & \\
8. Large Tracts (Avg. Pre-Merger Levels) & -2.233 & -207.6 & 43,593 \\
& $(0.919)$ & $(80.58)$ & \\
\hline
\end{tabular}

Source: FFIEC, author's own calculations. Table shows reduced form estimates of Equation 4 where the dependent variable is annual, tract-level small business loan originations in Column 1 and the dollar volume of lending in Column 2. All specifications include the full set of baseline controls interacted with year dummies along with tract and county-by-year fixed effects. Specification 1 is the baseline estimate from Table 7 . Specifications 2 and 3 drop observations where the number of loans is in either the bottom or top $5 \%$ of the distribution. Specifications 5 and 6 , respectively, drop the $5 \%$ smallest and $5 \%$ largest tracts in the sample where tracts are ranked according to their level of lending in the year 2000. Specifications 7 and 8, respectively, drop the $5 \%$ smallest and $5 \%$ largest tracts in the sample where tracts are ranked according to their average level of lending in the pre-merger years. See Appendix Section 1 for further details. Robust standard errors are clustered at the county level and are in parentheses. 
Table A.4: Log Dependent Variables

\begin{tabular}{ccc}
\hline \hline & $(1)$ & $(2)$ \\
& $\log (\#$ Loans $)$ & $\log (\$$ Volume $(000 \mathrm{~s}))$ \\
\hline \multirow{2}{*}{$\delta_{R F}$} & -0.0242 & -0.0284 \\
& $(0.0110)$ & $(0.0168)$ \\
& & \\
$\mathrm{N}$ & 45,160 & 43,033 \\
\hline
\end{tabular}

Source: FFIEC, author's own calculations. Table shows reduced form estimates of Equation 4 where all columns include the full set of baseline controls interacted with year dummies along with tract and county-by-year fixed effects. The dependent variables are the logs of annual, tract-level small business loan originations and the dollar volume of originations, respectively, and have been bottom-coded at 35 loans. Robust standard errors are clustered at the county level and are in parentheses.

Table A.5: Reduced Form Effect on Mortgages, by Mortgage Type

\begin{tabular}{lcccccc}
\hline \hline \multirow{2}{*}{ Coefficient } & $\begin{array}{c}(1) \\
\text { Purchase }\end{array}$ & $\begin{array}{c}(2) \\
\text { HE } \\
\text { \# Loans }\end{array}$ & $\begin{array}{c}(3) \\
\text { Refi }\end{array}$ & $\begin{array}{c}(4) \\
\text { Purchase } \\
\text { \$ Volume (000s) }\end{array}$ & $\begin{array}{c}(5) \\
\text { HE }\end{array}$ & $\begin{array}{c}\text { Refi } \\
\delta_{R F}\end{array}$ \\
& -1.018 & 0.0630 & 0.300 & -133.0 & -40.20 & 259.3 \\
& $(1.619)$ & $(0.162)$ & $(1.373)$ & $(305.5)$ & $(28.70)$ & $(388.9)$ \\
& & & & & & \\
Obs. & 45,505 & 45,505 & 45,505 & 45,682 & 45,682 & 45,682 \\
\hline
\end{tabular}

Source: FFIEC, author's own calculations. Table presents reduced form estimates of Equation 4, where the dependent variable is mortgage originations, by mortgage type. Purchase are home purchase mortgages, HE are home equity loans, and Refi are refinancings. Robust standard errors are clustered at the county level and are in parentheses.

Table A.6: Crisis Mergers

\begin{tabular}{llcc}
\hline \hline Buyer & Target & Year Approved & FDIC Assistance \\
\hline & Commerce Bank & 2008 & \\
TD BankNorth & Washington Mutual Bank & 2008 & $\mathrm{X}$ \\
JPMorgan Chase Bank & Wachovia Bank & 2008 & \\
Wells Fargo Bank & Downey Savings and Loan & 2008 & $\mathrm{X}$ \\
U.S. Bank & National City Bank & 2008 & \\
PNC Bank & Colonial Bank & 2009 & $\mathrm{X}$ \\
Branch Banking and Trust Company & Xnited Commercial Bank & 2009 & $\mathrm{X}$ \\
East West Bank & Guaranty Bank & 2009 & $\mathrm{X}$ \\
Compass Bank & & \\
\hline
\end{tabular}

Source: FDIC. Table shows mergers that occurred during the financial crisis. FDIC Assistance denotes those that received financial assistance from the FDIC. 
Table A.7: RF and IV Estimates Using Crisis Mergers

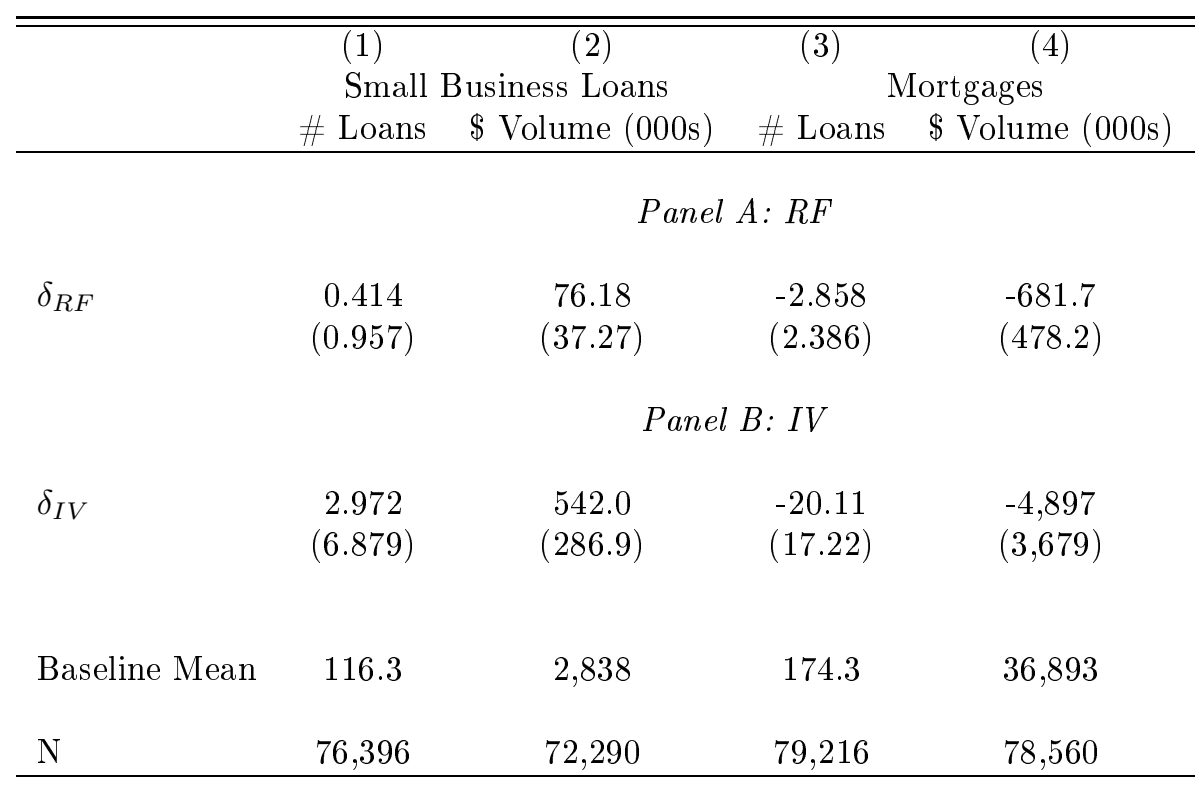

Source: FFIEC, author's own calculations. Table shows reduced form and IV estimates of Equation 4 using only the mergers listed in Table A.6. All columns include the full set of baseline controls interacted with year dummies along with tract and county-by-year fixed effects. The baseline mean is calculated for Exposed tracts in $\tau=-1$. Robust standard errors are clustered at the county level and are in parentheses. 